\title{
Teachers' Perceptions Indicate Success for Harvest of the Month Nutrition Education Program
}

\author{
Kristen Evans, Keiko Goto, Cindy Wolff, Martin Frigaard and Stephanie Bianco-Simeral \\ California State University, Chico
}

\begin{abstract}
The objective of this study was to examine teachers' attitudes, beliefs, classroom practices and perceptions of students' nutrition-related behaviors. The study involved 419 K-6th grade teachers participating in the Harvest of the Month (HOTM) program in fifty low-income schools from 19 school districts in the Sierra Cascade region of northern California. The independent variables were the teachers' implementation level of the HOTM program and encouragement level of vegetable and fruit consumption. The dependent variables were teachers' attitudes and beliefs about their ability to provide nutrition education, classroom practices and their perceptions of students' nutrition-related behaviors. Data were analyzed using descriptive statistics and multiple ordinal logistic regression models. The analysis accounted for number of years teaching, county location of school, and grade. Implementation level of the HOTM program was significantly related to teachers' perception of student nutrition-related behaviors. Additionally, teachers' perceptions of improvements in their students' behaviors were positively associated the level of encouragement they report to give their students to consume fruits and vegetables. Therefore, levels of both HOTM program implementation and fruit and vegetable consumption encouragement were associated with positive outcomes. Study results support the effectiveness of the HOTM program and identify a need for teacher trainings to increase the levels of nutrition education and encouragement for students to make healthier food choices.
\end{abstract}

(C) 2012 Californian Journal of Health Promotion. All rights reserved.

Keywords: Elementary school students, school-based nutrition education, teachers, fruit and vegetable consumption, Harvest of the Month

\section{Introduction}

Childhood obesity remains a paramount public health concern in the United States. The overweight and obesity rates in California and in northern California including Butte, Tehama, and Glenn Counties, exceed the national average of 31.7\% (Ogden and Carroll, 2010). According to the 2008 California Pediatric Nutrition Surveillance, the overweight and obesity state rate for youth ages 5-19 years old was $41.1 \%$, representing an increase of nearly five percent since 1999 (Polhamus, Dalenius, Mackentosh, Smith, \& Grummer-Strawn, 2009a).

The evidence of dietary behaviors that contribute to high obesity rates among children is equally concerning. The epidemiological evidence indicates an association between overweight status and a diet containing high amounts of soft drinks, fats and oils, and sodium. The opposite is true for diets that include plentiful fruits, vegetables, legumes, low-fat milk and other animal products (Boumtje, Huang, Lee, \& Lin, 2005). Additionally, diets higher in fruits and vegetables are protective against numerous chronic illnesses and unhealthy weight gain throughout adulthood (Hu, 2003; Hung et al., 2004; Riboli \& Norat, 2003).

\section{School-based Nutrition Interventions}

If parents are the gatekeepers of a child's home nutrition environment, then schools represent the "gatekeepers of nutritionally sound practices in the education environment" (Sorof, Lai, Turner, Poffenbarger \& Portman, 2004). A school day provides teachers and staff with the opportunity 
to assist in establishing healthy behaviors (Kropski, Keckley, \& Jensen, 2008; Story, Nanney, \& Schwartz, 2009). Nutrition education interventions have been conducted in the school environment to help support and sustain these healthy behavior changes. The most effective interventions have used multicomponent strategies that include fruit and vegetable tastings, cooking demonstrations, fruit and vegetable storybooks, garden-enhanced nutrition education, parent flyers, parent involvement, cafeteria posters, school foodservice staff encouragement, stickers and other incentives, classroom curricula, positive role modeling, and physical activity promotion (Blanchette \& Brug, 2005).

\section{Effects of School-based Nutrition Interventions on Fruit and Vegetable Consumption}

An essential evaluation component of nutrition education interventions is fruit and vegetable consumption. Nutrition education programs that incorporate frequent exposure to unfamiliar foods are successful at increasing rates of fruit and vegetable consumption (Knai, Pomerleau, Lock, \& Mckee, 2006; Lakkakula et al., 2011; Wardle et al., 2003). In similar research, sixthgrade adolescents who participated in nutrition education with garden-based activities increased their fruit and vegetable intake more than comparison groups (McAleese \& Rankin, 2007). Voorhees et al. (2011) demonstrated that when students had previously tasted a fruit or vegetable they were more likely to eat it (Voorhees, Goto, Bianco-Simeral, \& Wolff, 2011).

\section{Teachers' Roles in School-based Nutrition Interventions}

Multicomponent school-based nutrition education programs provide teachers with a variety of tools to positively influence nutrition behaviors. Teachers consistently report high preferences for nutrition curriculum programs that promote fruits and vegetables through tastings and associated in-class lessons (BlomHoffman, 2008; Perry et al., 2004; Reinaerts, De Nooijer, Candel, \& De Vries, 2006; Reynolds et al., 2000; Wang et al., 2010; Wood, Wolff, Bianco-Simeral, \& Goto, 2011).
Research indicates that higher levels of implementation of program elements (fruit and vegetables tastings, cooking demonstrations, classroom curriculum) may be associated with higher levels of fruit and vegetable consumption among students (Wang et al., 2010; Wood, Wolff, Bianco-Simeral, \& Goto, 2011). Story and colleagues (2000) implemented a nutrition education program that consisted of behavioral classroom curriculum, parental involvement, and food service modifications. They reported that positive feedback was received from teachers about the effectiveness of their curriculum, the importance of eating fruits and vegetables, and a high level of self-efficacy in being able to teach the program content. Teachers also reported that their own usual fruit and vegetable consumption increased after teaching the curriculum (Story et al., 2000). A similar study has also shown that teachers tend to be confident in their ability to provide multicomponent nutrition education programs to students (Reinaerts, De Nooijer, \& De Vries, 2007).

Evidence indicates that levels of implementation and the teachers' encouragement of multicomponent nutrition messages positively affect student outcomes, such as increased fruit and vegetable consumption (Knai, Pomerleau, Lock, \& Mckee, 2006; Lakkakula et al., 2011; Wardle et al., 2003). These findings indicate that teachers' attitudes, beliefs, and level of both program implementation and encouragement of program components desired behavior changes can influence student outcomes.

\section{Harvest of the Month Program}

The Harvest of the Month Program (HOTM) was created by the Network for a Healthy California as a multicomponent school nutrition curriculum program that is standardized, cost effective, replicable, and convenient. The Network for a Healthy California is a statewide social marketing program and is funded in part by the United States Department of Agriculture (USDA). The HOTM curriculum provides teachers and schools with materials and activities that correspond with a monthly featured produce item. This comprehensive curriculum includes fruit and vegetable tastings, classroom cooking demonstrations, cafeteria 
posters showcasing nutritional information and meal options, story books related to the monthly fruit or vegetable, Farmer of the Month newsletters promoting farm to fork, HOTM newsletters for parents, and HOTM classroom workbooks. The HOTM objectives are to assist teachers and schools in efforts to improve students' access, preference, and knowledge of fruits and vegetables (especially those grown locally in California); as well as increase daily physical activity (Network for a Health California, Harvest of the Month Program, 2007). This program attempts to unite the classroom, cafeteria, home, and community to promote healthy behaviors, specifically in low resource schools (Network for a Health California, Harvest of the Month Program, 2007).

Previous research on teachers participating in the Harvest of the Month (HOTM) program reported a positive change in student nutritionrelated attitudes and behaviors and teachers' classroom practices (Wood, Wolff, BiancoSimeral, \& Goto, 2011). Though studies have been conducted on specific components of the HOTM program, there remains a scarcity of research specific to the impact of levels of program implementation or encouragement of fruit and vegetable consumption on teachers' classroom practices and their perceptions of student behavioral outcomes.

The primary objective of this study was to evaluate the impact of teachers' implementation level of six components of the HOTM program on teachers' attitudes and beliefs about nutrition education, teachers' classroom practices, and teachers' perceptions of student behaviors. The association between the encouragement level of fruit and vegetable consumption during the intervention and teachers' perceptions of student behaviors was also investigated. The current study provides insight into the relationship between classroom environments, teacher nutrition-related perspectives, and the teachers' discernment of changes in student health behaviors. Findings also have implications for the interaction between classroom practices and districts' school wellness policy implementation.

\section{Methods}

\section{Study Design}

The current study includes a post survey with an intervention group only. Intervention schools receiving the HOTM program have a $\geq 50 \%$ student participation rate in the free or reduced price National School Meal Program.

\section{Participants and Recruitment}

Survey participants were elementary school teachers in the Sierra Cascade region of California who participated in the HOTM program during the current school year. Surveys were distributed to teachers during the last month of the school year. No incentives were provided for completing in the survey and teachers were not required to complete the survey in order to continue their participation in the HOTM program. A total of 753 surveys were distributed to K-6th grade teachers in 49 schools in 19 participating school districts in four counties (Butte, Glenn, Tehama, and Colusa). The overall survey response rate was $55.6 \%(\mathrm{n}=$ 419 teachers). This response rate is consistent with previous years of HOTM survey collection (Wood, Wolff, Bianco-Simeral, \& Goto, 2011). The on-line SurveyMonkey response rate for the one school district out of 19 using this method of survey distribution was $61.5 \%$. This study and its procedures were approved by the California State University, Chico Human Subjects Research Committee. Consent for participation in teacher surveys was obtained via signed letters from school administrators.

\section{Measurement Tool}

A two-page teacher survey was used to evaluate process and outcome measures for HOTM participation. The original teacher survey was created in 2005 and has been revised each year in order to streamline the survey and refine ongoing data collection methods. The current survey was adapted from the survey used by Wood, Wolff, Bianco-Simeral and Goto (2011) in a previous evaluation of the HOTM program. The modified survey included additional questions assessing school wellness policy knowledge and implementation. The survey was approved by the Network for a Healthy 


\section{California's Research and Evaluation Division.}

The process evaluation section of the survey was comprised of a list of the of the HOTM program components. Teachers were asked how many months during the current school year they had participated in each of the six HOTM components listed below.

1. Fruit and vegetable tastings

2. Classroom cooking demonstrations

3. 'Do-It-Yourself' classroom tastings

4. Book of the month activities

5. Farmer of the month flyer discussions

6. Student workbook activities

The survey outcome variables of interest consisted of the following: six statements addressing how often teachers were encouraging healthy classroom practices which were coded "Never," "1x/ mo.," "2-3x/mo.," "1x/wk.," "24x/wk.," and "Every day."; eight statements about the teacher's classroom practices in relation to nutrition which were coded "Always," "Frequently," "Sometimes" and "Never."; and five statements addressing the teacher's perceptions of student behaviors. Examples of these statements included: "students are more willing to taste a new fruit or vegetable. There were seven statements referring to teachers' attitudes and beliefs about nutrition education. Examples of these statements included: "I am confident in my ability to provide nutrition education," and "I am confident that if I teach nutrition, my students will increase their nutrition knowledge." All items addressing teachers' perceptions, attitudes and beliefs were ranked on a 4-point Likert scale and later recoded to a 3-level scale $(3=$ "Strongly Agree," 2 = "Agree," $1=$ "Disagree/Strongly Disagree).

Lastly, three survey questions addressed teachers' knowledge and adherence to school wellness policies. These statements included, "I know the details of my district's school wellness policy," "I follow my district's school wellness policy," and "My school/school district follows the school wellness policy."
The independent variables for this study were the teachers' implementation level of the HOTM program and encouragement level of fruit and vegetable consumption. The dependent variables included teachers' attitudes and beliefs about nutrition education, classroom practices, perceptions of students' behaviors, and teachers' knowledge and adherence to school wellness policies.

\section{Procedures}

The survey was distributed and collected during the spring of 2011. The survey was made available as a paper and digital copy (via SurveyMonkey), and teachers were notified about the option to complete the survey through email and school district staff meetings. All teachers had one week to complete the survey. Researchers collected the completed surveys from the schools and downloaded the completed online surveys at the culmination of the data collection period.

\section{Data Analysis}

To measure program implementation, a new variable was created to indicate the quantity and frequency of program elements that each teacher used during the school year. This new scale was created by summing the six variables that were used to measure the implementation levels of individual program components identified previously. Teachers implementing three or more components per month for the entire school year ( $\geq 27$ total HOTM activities/year) were coded high implementers (HI). In contrast, teachers who implemented less than three components per month during the school year ( $<27$ of total HOTM activities) were considered low implementers (LI). This new measure had a range of 0 to 54, and the average number of HOTM activities implemented was 25.6 over the course of the school year. Using this categorization method yielded approximately equal numbers of teachers in the two groups: 208 high implementers (HI) and 211 low implementers (LI). This new measure enabled an examination of the relationships among implementation level and the teachers' classroom practices, attitudes and beliefs about 
nutrition education, perceptions of student behaviors, and teachers' knowledge and adherence to school wellness policies.

The "teachers' encouragement level" variable was created by recoding the existing survey responses into an independent variable representing the encouragement level of fruit and vegetable consumption. The teachers reported encouraging students to eat vegetables and fruits as "Always," "Frequently," and "Sometimes." "Never" was included as a survey item, but not in the independent variable given that only one teacher reported never encouraging students to eat fruits and vegetables. This variable allowed an investigation into the relationship between encouragement level and teachers' perceptions of student behaviors.

Data were analyzed using SPSS version 19, 2011, SPSS Inc, Chicago. IL. Descriptive statistics were computed for all variables and were presented as percentages, means, and standard deviations. Ordinal logistic regression models were used to test the hypotheses that levels of both HOTM program implementation and encouragement of fruit and vegetable consumption were predictors of the teachers' classroom practices, attitudes and beliefs about nutrition education, perceptions of student behaviors, and knowledge or adherence to school wellness policies. Covariates in this analysis included grade, number of years teaching, and county location for schools (Butte, Glenn, Tehama, or Colusa). These multiple regression analyses were used to calculate odds ratios and confidence intervals for dependent variable scores. The odds ratio represents the likelihood that higher level responses for independent variables (i.e., "Always") were associated with higher level responses on dependent outcome variables (i.e, "Strongly Agree"). The level of $\leq 0.05$ was used to indicate statistical significance.

Table 1

K-6 Teachers by Grade for 2010-2011 School Year

\begin{tabular}{|c|c|c|c|c|}
\hline \multirow[b]{2}{*}{ Grade } & \multirow[b]{2}{*}{ Teachers } & \multirow[b]{2}{*}{$\%$} & \multicolumn{2}{|c|}{$\begin{array}{c}\text { Average Number of Years } \\
\text { Teaching }\end{array}$} \\
\hline & & & Mean & SD \\
\hline Kindergarten & 67 & 16 & 17.9 & 8.3 \\
\hline $1 \mathrm{st}$ & 61 & 14.6 & 16.6 & 9.4 \\
\hline 2nd & 71 & 16.9 & 17.2 & 8.1 \\
\hline 3rd & 71 & 16.9 & 18.1 & 7.8 \\
\hline 4th & 58 & 13.8 & 16.2 & 7.7 \\
\hline 5 th & 57 & 13.6 & 17.5 & 8.9 \\
\hline 6th & 34 & 8.1 & 12.9 & 6.7 \\
\hline Total & 419 & 100 & 16.9 & 8.3 \\
\hline
\end{tabular}

\section{Results}

\section{Description of Sample}

Table 1 shows descriptive statistics for the 419 teachers who completed the survey. The overall average number of years spent teaching was 16.9. As presented in Table 2, independent samples t-test results indicate that high implementers (HI) and low implementers (LI) differed from each other on various outcomes. HOTM program components achieving the highest levels of implementation (ranging from 1 - 9 times per year) among all teachers included fruit and vegetable tastings $(\mathrm{M}=8.66$; $\mathrm{SD}=1.41)$, Farmer of the Month flyer $(\mathrm{M}=$ 6.32 ; $\mathrm{SD}=3.65)$, and student workbooks $(\mathrm{M}=$ 4.41; $\mathrm{SD}=3.90)$. Teachers in the HI group were significantly more frequent users of all six 
Evans, K., Goto, K., Wolff,C., Frigaard, M. \& Bianco-Simeral, S. / Californian Journal of Health Promotion 2012, Volume 10,

program components with the highest rates for the Book of the Month, Farmer of the Month flyer, and student workbook components of the program.

Table 2

Mean Scores of Harvest of the Month (HOTM) Activities by Implementation Group ${ }^{\text {a }}$

\begin{tabular}{|c|c|c|c|c|}
\hline \multirow[t]{2}{*}{$\begin{array}{l}\text { Harvest of the Month Program } \\
\text { Components }\end{array}$} & \multicolumn{2}{|c|}{$\begin{array}{l}\text { Higher Implementers }{ }^{\mathrm{b}} \\
(\mathrm{n}=\mathbf{2 0 8}, \mathbf{4 9 . 6 \% )}\end{array}$} & \multicolumn{2}{|c|}{$\begin{array}{c}\text { Lower Implementers } \\
\quad(\mathbf{n}=\mathbf{2 1 1}, \mathbf{5 0 . 3 \%})\end{array}$} \\
\hline & Mean & SD & Mean & SD \\
\hline 1. Fruit and vegetable tastings $* * *$ & 9.00 & 0.07 & 8.33 & 1.93 \\
\hline 2. Cooking demonstrations*** & 1.65 & 2.58 & 0.55 & 1.11 \\
\hline 3. DIY (Do-It-Yourself) tastings $* * *$ & 3.06 & 3.61 & 1.00 & 1.95 \\
\hline 4. Book of the month*** & 4.95 & 3.65 & 1.50 & 2.30 \\
\hline 5. Farmer of the month flyer*** & 8.13 & 2.21 & 4.54 & 3.90 \\
\hline 6. Student workbooks*** & 6.40 & 3.48 & 2.45 & 3.25 \\
\hline Avg. \# of total HOTM components*** & 33.19 & 15.60 & 18.37 & 14.44 \\
\hline
\end{tabular}

Implementation Level and Teachers' Attitudes and Beliefs

Teachers' attitudes and beliefs about nutrition education by level of HOTM implementation groups were examined using ordinal logistic regression controlling for grade, number of years teaching, and school county location. HI teachers, in comparison with LI teachers, were significantly more likely to report higher Likert responses for all survey items pertaining to attitudes and beliefs about nutrition education ( $\mathrm{p}$ $<0.05)$.

\section{Implementation Level and Teachers' Classroom Practices}

Ordinal logistic regression was used to compare teachers' classroom practices between HI and LI groups controlling for grade, number of years teaching, and county location of school. Teachers in the HI group were significantly more likely to report "Always" and "Frequently" for the statement, "I involve parents in nutrition education classroom activities" $(\mathrm{p}<0.001)$.

\section{Implementation Level and Teachers' Perceptions of Student Behaviors}

Ordinal regression models indicated significant relationships between teachers' perceptions of student behaviors and implementation level groups. As with previously reported regression models, grade, number of years teaching, and county location of school were included as covariates. As shown in Table 3, HI teachers were significantly more likely to report higher Likert scores compared to their LI counterparts for all student behaviors. For example, the odds of reporting higher Likert scores for the statement, "students are more receptive to tasting/eating vegetables," were 2.5 times higher among HI teachers compared to LI teachers. 
Table 3

Adjusted Odds Ratios for Teachers' Perceptions of Student Behaviors by Level of Harvest of the Month Implementation

\begin{tabular}{llcc} 
Dependent ${ }^{\mathbf{a}}$ (Outcome Variables) & Implementation Group & OR $^{\mathbf{b}}$ & 95\% CI \\
\hline $\begin{array}{l}\text { Students express more interest in } \\
\text { improving their eating habits** }\end{array}$ & High Implementers & 2.29 & $1.46-3.56$ \\
& Low Implementers & 1.00 & \\
$\begin{array}{l}\text { Students express more interest in } \\
\text { increasing their physical activity*** }\end{array}$ & High Implementers & 2.11 & $1.35-3.31$ \\
& Low Implementers & 1.00 & \\
& High Implementers & 2.47 & $1.61-3.81$ \\
$\begin{array}{l}\text { Students are more receptive to } \\
\text { tasting/eating vegetables*** }\end{array}$ & Low Implementers & 1.00 & \\
& High Implementers & 1.93 & $1.26-2.96$ \\
$\begin{array}{l}\text { Students are more receptive to } \\
\text { tasting/eating fruits* }\end{array}$ & Low Implementers & 1.00 & \\
& High Implementers & 1.30 & $0.86-1.97$ \\
$\begin{array}{l}\text { Students show less interest in drinking } \\
\text { soda and sweet drinks }\end{array}$ & Low Implementers & 1.00 & \\
\hline
\end{tabular}

Note. ${ }^{\mathrm{a}}$ Dependent variables are on a 3-level scale $(3=$ Strongly Agree, 2 = Agree, 1 = Disagree/Strongly

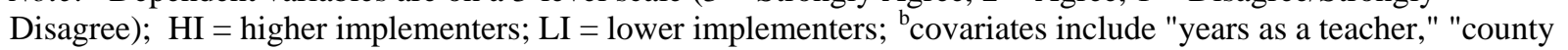
location," and "grade;" OR = odds ratio; C.I. = confidence interval; $* p<0.05, * * * p<0.001$.

\section{Encouragement Level and Teachers' Perceptions of Student Behaviors}

The current study also examined the impact of teachers' encouragement level of fruit and vegetable consumption compared to the teachers' perception of student behaviors, once again controlling for grade, years of teaching, and school county location (Table 4). In this ordinal regression model, teachers providing higher levels of encouragement were significantly more likely to report higher Likert scores for student behaviors.

\section{Implementation and Encouragement Levels and School Wellness Policies}

Neither implementation level of the HOTM program nor encouragement level of fruit and vegetable consumption was a significant factor for teachers' statements addressing school wellness policies (i.e. "My school/school district follows the school wellness policy", "I know the details of my district's school wellness policy" and "I follow my district's school wellness policy"). 
Table 4

Adjusted Odds Ratios of Teachers' Perceptions of Student Behaviors by Encouragement Level of Fruit \& Vegetable Consumption

\begin{tabular}{llll}
\hline Dependent Variables & & Oncouragement Level & 95\% $\mathbf{C I}^{\mathbf{b}}$ \\
\hline $\begin{array}{l}\text { Students express more interest in } \\
\text { improving their eating habits }\end{array}$ & Always*** & 4.91 & $2.48-9.72$ \\
& Frequently & 1.79 & $0.94-3.98$ \\
& Sometimes & 1.00 & \\
$\begin{array}{l}\text { Students express more interest in } \\
\text { increasing their physical activity }\end{array}$ & Always*** & 3.03 & $1.57-5.84$ \\
& Frequently & 1.78 & $0.95-3.34$ \\
& Sometimes & 1.00 & \\
$\begin{array}{l}\text { Students are more receptive to } \\
\text { tasting/eating vegetables }\end{array}$ & Always*** & 3.20 & $1.69-6.07$ \\
& Frequently & 1.70 & $0.92-3.12$ \\
Students are more receptive to & Sometimes & 1.00 & \\
tasting/eating fruits & Always** & 2.81 & $1.50-5.23$ \\
& Frequently & 1.52 & $0.86-2.75$ \\
Students show less interest in drinking & Sometimes & 1.00 & \\
soda and sweet drinks & Always** & 2.76 & $1.49-5.11$ \\
& Frequently & 1.65 & $0.92-2.97$ \\
\hline & Sometimes & 1.00 & \\
\hline
\end{tabular}

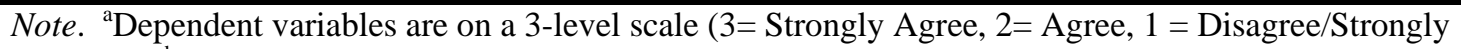


interval; ** $\mathrm{p}<0.01, * * * \mathrm{p}<0.001$.

\section{Discussion}

The purpose of this investigation was to evaluate the influence of teachers' implementation level of HOTM program components on their attitudes and beliefs about nutrition education, nutrition-related classroom practices, and perceptions of student behaviors. The findings in this study indicate that higher levels of implementation of the HOTM program are associated with positive teacher attitudes and beliefs about nutrition education as well as their perceptions of changes in their students' behaviors. Higher implementation level was also associated with increased involvement of parents in classroom nutrition activities. This study also discovered that higher encouragement levels of fruit and vegetable consumption are associated with a positive perception of student behaviors. These findings are consistent with previous research suggesting that teachers can be effective in influencing dietary behaviors including the increased consumption of fruits and vegetables (Kropski, Keckley, \& Jensen, 
2008; Reinaerts, De Nooijer, \& De Vries, 2007; Story, Nanney, \& Schwartz, 2009; Wang et al., 2010; Wood, Wolff, \& Bianco-Simeral, Goto, 2011).

The elements of the Harvest of the Month program achieving the highest levels of implementation included the fruit and vegetable tastings, Farmer of the Month flyer, and student workbooks. Fruit and vegetable tastings are consistently among the most implemented components of nutrition education programs, possibly due to the effectiveness of repeated exposures in eliciting increased consumption (Knai, Pomerleau, Lock, \& Mckee, 2006; Lakkakula et al., 2011; Voorhees, Goto, BiancoSimeral, \& Wolff, 2011). Blom-Hoffman (2008) also reported similar teachers' preferences among other components (e.g., CD-ROM, AM announcements, lunchtime stickers, take-home books) and their effectiveness in improving students' nutrition behaviors (Blom-Hoffman, 2008). Related research has also demonstrated that student preferences for fruits and vegetables increased in high program implementation schools (Reinaerts, De Nooijer, Candel, \& De Vries, 2006; Wang et al., 2010). The combination of these findings suggests that the effectiveness of the HOTM program to influence students' preference for and consumption of fruits and vegetables is contingent upon teachers implementing numerous components of the program.

Our findings show that higher teacher implementation levels of program components are associated with teachers' positive attitudes and beliefs about providing nutrition education to children. A similar relationship was found between implementation levels and the types of foods promoted at classroom celebrations (i.e., "I promote other birthday treats, besides high sugar, high fat foods like cake or cookies"), as well as involving parents in nutrition education. These findings are not surprising, considering it is plausible that teachers with positive attitudes and beliefs about nutrition education would likely use more HOTM components in their classroom.
This evaluation indicated that approximately $82 \%$ of the teachers in this sample reported that they "Always" (35.4\%) or "Frequently" (47.4\%) encouraged students to eat vegetables and fruits. According to previous investigations, teachers involved in a multicomponent nutrition education program reported high preference and implementation rates for both the curriculum lessons and the tasting activities (Perry et al., 2004; Reynolds et al., 2000; Reinaerts, De Nooijer, Candel, \& De Vries, 2006; Story et al., 2000; Wang et al., 2010). Teachers with the highest encouragement levels of fruit and vegetable consumption also reported higher scores for all student behaviors, such as improved receptiveness to trying fruits and vegetables and increased interest in physical activity. This finding implies that if teachers presume that they are encouraging fruit and vegetable consumption, then they might also perceive that they are positively affecting their students' behaviors. This finding is consistent with previous research showing that verbal encouragement by food service staff was significantly associated with increased consumption of fruits and vegetables (Perry et al., 2004).

In summary, higher implementation of the HOTM program components is linked to significantly higher scores for variables related to teachers' attitudes, beliefs, classroom practices, and perception of student behaviors. Results also show that higher encouragement levels of fruit and vegetable consumption is linked to higher scores on teachers' perceptions of student behaviors (interest in improving their eating habits, less interest in drinking soda and sweet drinks, and more receptive to tasting/eating fruits and vegetables). These findings are similar to recent research measuring teachers' discernment of student nutritional behaviors (Wood, Wolff, \& Bianco-Simeral, Goto, 2011). The current study indicates that multicomponent programs such as HOTM may improve teachers' abilities to effectively encourage their students to adopt healthful nutrition-related behaviors. 


\section{Limitations}

The study's methodology was limited by the post-only design and the lack of a control group. A pre/post or longitudinal intervention research design with a control group would have allowed the authors to see any behavior changes over the course of the school year. Additionally, outcome variables for students' behaviors were reported as perceptions by teachers, rather than more objective measurements of students' behaviors on diet and physical activity. Finally, because the overall survey response rate was only $55.6 \%$, our findings might not be representative of all teachers who were involved in the HOTM program.

\section{Conclusion}

The Harvest of the Month program appears to be an effective method for promoting positive nutrition-related behaviors among elementary school teachers and students. Levels of program implementation and encouragement of fruit and vegetable consumption were significant factors associated with teachers' perceptions of improvements in student behavioral outcomes. Our findings also support previous research on the preference and effectiveness of multicomponent tasting programs in promoting nutrition-related behavior changes in the school environment. Barriers that affect multicomponent program implementation and encouragement, such as program complexity and feasibility of acquiring program elements, need to be identified and mitigated to ensure program success (Reinaerts, De Nooijer, \& De Vries, 2007).

It is possible that nutrition education interventions could be further integrated with school wellness policies. The relationship between teachers' knowledge of knowledge and adherence to school wellness policies was insignificant in this investigation and should be addressed in future research.

\section{Acknowledgements}

The Harvest of the Month study was funded by the Federal Financial Participation reimbursement funding through United States Department of Agriculture Supplemental Nutrition Assistance Program (SNAP) via a contract with the California Department of Public Health's Network for a Healthy California. The authors wish to thank the staff and student interns at the CSU, Chico Center for Nutrition and Activity Promotion and our study participants for their support.

\section{References}

Blanchette, L., \& Brug, J. (2005). Determinants of fruit and vegetable consumption among 6-12-year-old children and effective interventions to increase consumption. Journal of Human Nutrition and Dietetics, 18, 431-443. doi: 10.1111/j.1365-277X.2005.00648.x

Blom-Hoffman, J. (2008). School-based promotion of fruit and vegetable consumption in multiculturally diverse, urban schools. Psychology in the Schools, 45(1), 16-27. doi: 10.1002/pits.20275

Boumtje, P., Huang, C., Lee, J., \& Lin, B. (2005). Dietary habits, demographics, and the development of overweight and obesity among children in the United States. Food Policy, 30, 115-128.

Hu, F. B. (2003). Plant-based food and prevention of cardiovascular disease: An overview. American Journal of Clinical Nutrition, 78, 544S-51S.

Hung, H. C., Joshipura, K. J., Jiang, R., Hu, F. B., Hunter, D., Smith-Warner, S. A.,...Willet, W.C. (2004). Fruit and vegetable intake and risk of major chronic disease. Journal of the National Cancer Institute, 96, 1577-1584

Knai, C., Pomerleau, J., Lock, K., \& Mckee, M. (2006). Getting children to eat more fruit and vegetables: A systematic review. Preventive Medicine, 42, 85-95. Retrieved from http://dx.doi.org/10.1016/j.ypmed.2005.11.012. Accessed January 20, 2012.

Kropski, J.A., Keckley, P. H., \& Jensen G. L. (2008). School-based obesity prevention programs: An evidence-based review. Obesity, 16, 1009-18. doi: 10.1038/oby.2008.29 
Evans, K., Goto, K., Wolff,C., Frigaard, M. \& Bianco-Simeral, S. / Californian Journal of Health Promotion 2012, Volume 10,

Lakkakula, A., Geoghan, J.P., Wong, W.P, Zanovec, M., Peirce, S.H., \& Turri, G. (2011). A cafeteriabased tasting program increased liking of fruits and vegetables by lower, middle, and upper elementary school-age children. Appetite, 57, 299-302. Retrieved from http://dx.doi.org/10.1016/j.appet.2011.04.010. Accessed January 16, 2012.

McAleese, D. J., \& Rankin, L. L. (2007). Garden-based nutrition education affects fruit and vegetable consumption in sixth-grade adolescents. Journal of American Dietetic Association, 107, 662-665. doi:10.1016/j.jada.2007.01.015

Network for a Healthy California (2007). Harvest of the Month Program. Retrieved from http://www.harvestofthemonth.com/program-overview.asp. Accessed January 17, 2012.

Ogden, C., \& Carroll, M. (2010). Prevalence of obesity among children and adolescents: United States, trends 1963-1965 through 2007-2008. Retrieved from http://www.cdc.gov/nchs/data/hestat/obesity_child_07_08/obesity_child_07_08.htm. Accessed January 9, 2012.

Perry, C.L., Bishop, D.B., Taylor, G.L., Davis, M., Story, M., \& Gray, C. (2004). A randomized school trial of environmental strategies to encourage fruit and vegetable consumption among children. Health Education and Behavior, 31(1), 65-76. doi: 10.1177/1090198103255530

Polhamus, B., Dalenius, K., Mackentosh, H., Smith, B., \& Grummer-Strawn, L. (2009a). Pediatric Nutrition Surveillance 2008 Report, Butte County. Atlanta: Centers for Disease Control and Prevention. Retrieved from http://www.cdc.gov/nccdphp/dnpa/pednss.htm. Accessed January 20, 2012.

Polhamus, B., Dalenius, K., Mackentosh, H., Smith, B., \& Grummer-Strawn, L. (2009b). Pediatric Nutrition Surveillance 2008 Report, California. Centers for Disease Control and Prevention. Retrieved from http://www.cdc.gov/nccdphp/dnpa/pednss.htm. Accessed January 3, 2012.

Reinaerts, E., De Nooijer, J., \& De Vries, N. (2007). Fruit and vegetable distribution program versus a multicomponent program to increase fruit and vegetable consumption: Which should be recommended for implementation? Journal of School Health, 77(10), 679-686. doi: 10.1111/j.1746-1561.2007.00251.x

Reinaerts, E., De Nooijer, J., Candel, M., \& De Vries, N. (2006). Increasing children's fruit and vegetable consumption: Distribution or a multicomponent programme? Public Health Nutrition, 10 (9), 939-947. doi: 10.1017/S1368980007665495

Reynolds, K., Franklin, F., Leviton, L., Maloy, J., Harrington, K.F., Yaroch, A.L... Jester, P. (2000). Methods, results, and lessons learned from process evaluation of the high 5 school-based nutrition intervention. Health Education and Behavior, 27, 177-186. doi: 10.1177/109019810002700204

Riboli, E \& Norat, T. (2003). Epidemiologic evidence of the protective effect of fruit and vegetables on cancer risk. American Journal of Clinical Nutrition, 78, 559S-5569S

Sorof, J. M., Lai, D., Turner, J., Poffenbarger, T., \& Portman, R. J. (2004). Overweight, ethnicity, and the prevalence of hypertension in school-aged children. Pediatrics, 113(3), 475-482. doi: 10.1542/peds.113.3.475

Story, M., Mays, R., Bishop, D., Perry, C. L., Taylor, G., Smyth, M., \& Gray, C. (2000). Increase fruit and vegetable consumption 5-a-day power plus: Process evaluation of a multicomponent elementary school program to increase fruit and vegetable consumption. Health Education and Behavior, 27(2),187-200. doi: 10.1177/109019810002700205

Story, M., Nanney, M., \& Schwartz, M. (2009). Schools and obesity prevention: Creating school environments and policies to promote healthy eating and physical activity. Milbank $Q 87,71-$ 100. doi: 10.1111/j.1468-0009.2009.00548.x

U.S. Department of Agriculture and U.S. Department of Health and Human Services. (2010). Dietary Guidelines for Americans, 2010. (7th Edition) Washington, DC: U.S. Government Printing Office. Retrieved from http://www.health.gov/dietaryguidelines/dga2010/DietaryGuidelines2010.pdf. Accessed January 10, 2012. 
Voorhees, J., Goto, K., Bianco-Simeral, S., \& Wolff C. (2011). Impact of the Harvest of the Month program on low-income Hmong and white middle school students. Journal of Nutrition Education and Behavior, 43 (4), 152-154. doi:10.1016/j.jneb.2011.01.011

Wang, M.C., Rauzon, S., Studer, N., Martin, A.C., Graig, L., Merlo, C., Crawford, P. (2010). Exposure to a comprehensive school intervention increases vegetable consumption. Journal of Adolescent Health, 47, 74-82.

Wang, Y, \& Beydoun, M. (2007). The obesity epidemic in the United States-gender, age, socioeconomic, racial/ethnic, and geographic characteristics: A systematic review and meta-regression analysis. Epidemiologic Reviews, 29, 6-28.

Wardle, J., Herrera, M., Cooke, L., \& Gibson, E. (2003). Modifying children's food preferences: The effects of exposure and reward on acceptance of an unfamiliar vegetable. European Journal of Clinical Nutrition, 57, 341-348. doi: 10.1038/sj.ejen.1601541

Wood, L., Wolff, C., Bianco-Simeral, S., \& Goto, K. (2011). Impact of a kindergarten through eighthgrade nutrition education program on student, teacher, and schoolwide practices. Journal of Nutrition Education and Behavior, 43(4), 145-147.

Author Information
Kristen Evans, MS
Former Graduate Student
California State University, Chico

Keiko Goto, $\mathrm{PhD} *$

Associate Professor

Department of Nutrition and Food Sciences

Assistant Director of Research and Evaluation

Center for Nutrition and Activity Promotion

California State University, Chico

Address: Chico, CA 95929-0002

Telephone number: 530-898-6767

Fax: 530-898-5586

E-mail address: kgoto@csuchico.edu

Cindy Wolff, PhD, MPA, RD

Director, Center for Nutrition and Activity Promotion

Professor, Department of Nutrition and Food Sciences, California

State University, Chico

Martin Frigaard, MA

Research Assistant, Center for Nutrition and Activity Promotion

Lecturer, Department of Kinesiology,

California State University, Chico

Stephanie Bianco-Simeral, MS, RD

Associate Professor, Department of Nutrition and Food Sciences Assistant Director of Operations, Center for Nutrition and Activity Promotion, California State University, Chico

* corresponding author 